\title{
ANÁLISE DE SITUAÇÃO DE SAÚDE DO TRABALHADOR COMENTADA E VIVENCIADA NO MUNICÍPIO DE ARUANÃ/GO
}

\author{
Larissa Di Oliveira Santhomé ${ }^{1}$ \\ Danniella Davidson Castro
}

\begin{abstract}
Resumo: $O$ mundo contemporâneo encontra-se em um curto-circuito sociometabólico em diversas áreas, em situações que provocam cada vez mais vulnerabilidade social e subjetiva, em uma retroalimentação de uma cadeira perversa, pois o sujeito que morre com o trabalho precisa dele. A intervenção no território foi feita a partir da análise de situação de saúde do trabalhador, que busca conhecer os fatores impactantes e de adoecimento nos trabalhadores. Partiu-se da inquietação dos técnicos em fiscalização sanitária de ambientes e processos de trabalho, na óptica de multiplicadores de vigilância em saúde do trabalhador, os dados epidemiológicos e as impressões vivenciadas junto à aldeia indígena e aos trabalhadores do SUS do município. Ao final, tem-se o panorama da saúde no território de Aruanã considerando as influências da população indígena.
\end{abstract}

Palavras-chave: Trabalhador; Curto-circuito; Vulnerabilidade; População Indígena.

\section{ANALYSIS OF THE HEALTH SITUATION OF WORKERS COMMENTED AND EXPECTED IN THE MUNICIPALITY OF ARUANÃ/GO}

\begin{abstract}
The contemporary world finds itself in a sociometabolic short circuit in several áreas, in situations that provoke more and more social and subjective vulnerability, in a feedback of a perverse chain, because the subject Who dies with the work needs it. The intervention in the territory was made from the analysis of health situation of the worker, Who seeks to know the impact factors and sickness in work-people. It was from the concern of the technicians in sanitary inspection of environments and work processes, from the perspective of multipliers of surveillance in the worker's health, the epidemiological data and the impressions lived next to the indigenous village and the SUS workers of the municipality. In the end, we have the panorama of health in the territory of Aruanã considering the influences of the indigenous population.
\end{abstract}

Keywords: Worker; Short-circuit; Vulnerability; Indigenous Population.

\footnotetext{
${ }^{1}$ Fisioterapeuta na Gerência de Vigilância em Saúde Ambiental e Saúde do Trabalhador Superintendência de Vigilância e Saúde do Estado de Goiás. fisiolarissadi@gmail.com.

${ }^{2}$ Psicóloga da Superintendência de Vigilância em Saúde do Estado de Goiás. dannidavidsonpsic@hotmail.com.

Estudos Geográficos, Rio Claro, 17: 106-115, jan./jun. 2019 (ISSN 1678-698X) http://www.periodicos.rc.biblioteca.unesp.br/index.php/estgeo
} 
Análise de situação de saúde do trabalhador...

\section{INTRODUÇÃO}

O mundo contemporâneo encontra-se em um curto-circuito sociometabólico em diversas áreas: a mineração com suas commodities - que varre do mapa territórios e populações inteiras na exploração brutal da terra, das águas e provoca horror, silêncio, angústia diante desse extermínio socioambiental; o agrotóxico - que tem sido chamado de a nova violência no campo, o desprezo e hostilidade com a população indígena em suas mais diversas formas, os trabalhadores do campo sendo assassinados, pessoas desaparecidas, trabalho escravo, trabalho infantil, a precarização do trabalho que vela e mostra sua face no cotidiano, são situações que provocam cada vez mais vulnerabilidade social e subjetiva, em uma retroalimentação de uma cadeia perversa, pois o sujeito desalentado que morre com o trabalho precisa dele.

Desde MARX (1818-1883) já era discutida a problemática da mais-valia, um conceito cunhado da economia para evidenciar a exploração do trabalhador. A mais valia consistia na diferença entre o valor do produto final, produzido pelo trabalhador e a remuneração que era paga a ele, de forma absurdamente desigual em que não Ihe era revertida nem mesmo uma parcela ínfima desse valor. Essa desvalorização da força de trabalho é o que constituía para o autor, a base da exploração capitalista, tão presente ainda nos dias atuais.

Para ANTUNES (2018) em que as fronteiras do trabalho estão cada vez mais tênues, onde os trabalhadores são cada dia mais expropriados dos seus direitos e que o trabalhador tem hoje, "o privilégio da servidão" de possuir um emprego.

Nesse contexto, como é impactada a saúde da população? Os povos indígenas que estão no centro do território? A conseqüente exploração da terra e da força de trabalho indígenas, além da perda da possibilidade de contar suas experiências, suas narrativas, tem causado um desamparo na população. Diante desse cenário terrível, dessa barbárie, como é possível se pensar em fazer saúde do trabalhador?

Uma tentativa é partir da análise de situação de saúde: o que impacta, adoece e mata os trabalhadores? Quem conhece e sabe do território são os agentes comunitários de saúde e os agentes de endemias, que através das suas andanças conhecem e enfrentam a realidade do cotidiano, dos profissionais de saúde da atenção básica, que acolhem os sujeitos, suas demandas, suas mazelas e suas dores.

A Vigilância em Saúde do Trabalhador, nessa linha de construção, faz conexões entre os agravos, os riscos, o processo produtivo e o território como um lugar de conflito, que denuncia a lógica da exploração, da mais valia, o jogo político no exercício de poder. Teixeira, Paim e Vilas Boas (2000) enumeram sete características básicas da Vigilância em saúde: intervenção sobre problemas de saúde (danos, riscos e/ou determinantes), ênfase em problemas que requerem atenção e acompanhamento contínuos, operacionalização do conceito de risco, articulação de ações promocionais, preventivas e curativas, atuação intersetorial, ações sobre o território, intervenção sob a forma de operações.

Nessa perspectiva, a Vigilância em Saúde do Trabalhador é, antes de tudo, uma intervenção política, que foi pensada como uma ação de pesquisa e intervenção no território de Aruanã, que convocou a palavra e a experiência do labor diário dos agentes comunitários de saúde, agentes de endemias, profissionais da Estudos Geográficos, Rio Claro, 17: 106-115, jan./jun. 2019 (ISSN 1678-698X) http://www.periodicos.rc.biblioteca.unesp.br/index.php/estgeo 
atenção básica e os técnicos da vigilância em Saúde do Estado, que articulou a política pública do Sistema Único de Saúde (SUS) com a vida social.

A partir da análise de situação de saúde do trabalhador, que busca conhecer os fatores impactantes e de adoecimento nos trabalhadores, tem-se o objetivo de caracterizar a população indígena e usuária do Sistema Único de Saúde (SUS). Partiu-se da inquietação dos técnicos em fiscalização sanitária de ambientes e processos de trabalho, na óptica de multiplicadores de vigilância em saúde do trabalhador, os dados epidemiológicos e as impressões vivenciadas junto à aldeia indígena e aos trabalhadores do SUS do município. Ao final, tem-se o panorama da saúde no território de Aruanã considerando as influências da população indígena como parte da agenda do V CIRCUITO DA SOCIOBIODIVERSIDADE- "Território, Alimento e a Questão Indígena" que aconteceu no município de Aruanã, estado de Goiás, entre os dias 11 a 15 de fevereiro de 2019.

O Sistema de Informação de Saúde do Sistema Único de Saúde concentra dados epidemiológicos sobre a população residente, a população trabalhadora, o perfil econômico e as condições de saúde. Os dados encontrados desenham timidamente as possibilidades de comportamento da área estudada e subsidia as decisões de saúde.

O município de Aruanã pertence à microrregião de Saúde Rio Vermelho com sede no município de Goiás e ocupa o segundo lugar em extensão $(6.050 \mathrm{~km} 2)$ e não está entre um dos mais populosos (menos de $4 \%$ da população da região de saúde estudada). Logo de início, percebe-se a riqueza natural do território que interage com a população e sua saúde e que justifica o desenvolvimento econômico no campo turístico e do comércio.

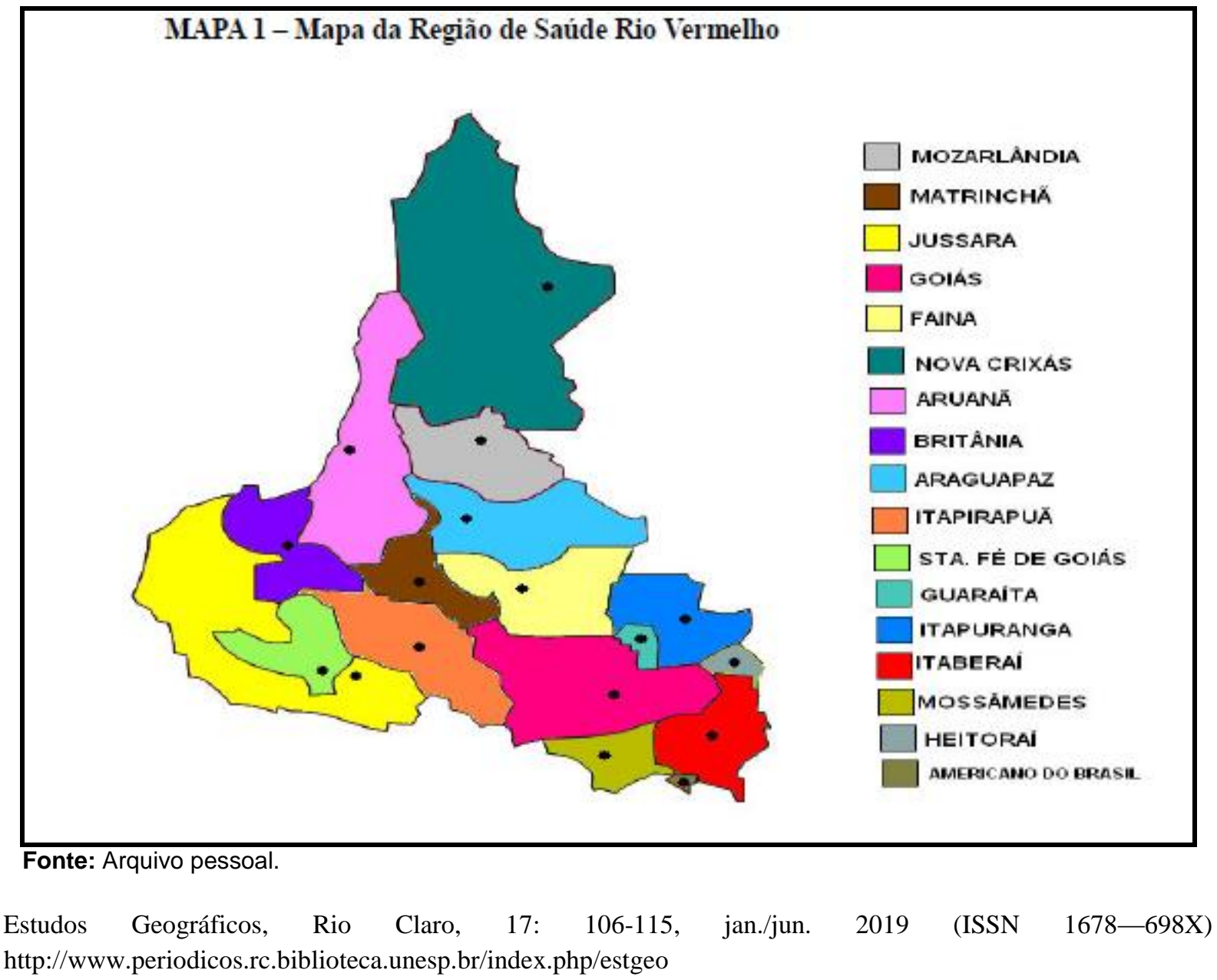


Tabela 1 - Perfil geral do município de Aruanã/GO

\begin{tabular}{|l|r|}
\hline População estimada [2018] & 9.635 pessoas \\
\hline População no último censo [2010] & 7.496 pessoas \\
\hline Densidade demográfica [2010] & 2,46 hab/km² \\
\hline Salário médio mensal dos trabalhadores formais (2016) & 1,8 salários mínimos \\
\hline Pessoal ocupado [2016] & 746 pessoas \\
\hline População ocupada [2016] & $8,3 \%$ \\
\hline Empresas registradas (CEMPRE 2016) & 126 empresas \\
\hline Empresas atuantes (CEMPRE 2016) & 122 empresas \\
\hline
\end{tabular}

Fonte: https://cidades.ibge.gov.br/brasil/go/aruana/panorama

A população geral do estado de Goiás passa de 6 milhões de residentes sendo que 8500 mil são indígenas, segundo dados de 2010.

Tabela 2 - População residente, por condição de indígena, segundo a situação do domicílio, Grandes Regiões e Unidades da Federação - Brasil 1991/2010

\begin{tabular}{|l|r|r|r|r|}
\hline \multirow{2}{*}{$\begin{array}{c}\text { Situação do } \\
\text { domicílio, Grandes }\end{array}$} & \multicolumn{4}{|c|}{2010} \\
\cline { 2 - 5 } $\begin{array}{c}\text { Regiões e Unidades } \\
\text { da Federação }\end{array}$ & \multicolumn{1}{|c|}{ Total } & Não indígena & Indígena & Sem declaração \\
\hline Total & 190.755 .799 & 189.931 .228 & 817.963 & 6.608 \\
\hline Centro-Oeste & 14.058 .094 & 13.927 .187 & 130.494 & 413 \\
\hline Mato Grosso do Sul & 2.449 .024 & 2.375 .716 & 73.295 & 13 \\
\hline Mato Grosso & 3.035 .122 & 2.992 .389 & 42.538 & 195 \\
\hline Goiás & 6.003 .788 & 5.995 .188 & 8.533 & 138 \\
\hline Distrito Federal & 2.570 .160 & 2.563 .894 & 6.128 & \\
\hline
\end{tabular}

Fonte: https://indigenas.ibge.gov.br/graficos-e-tabelas-2.html

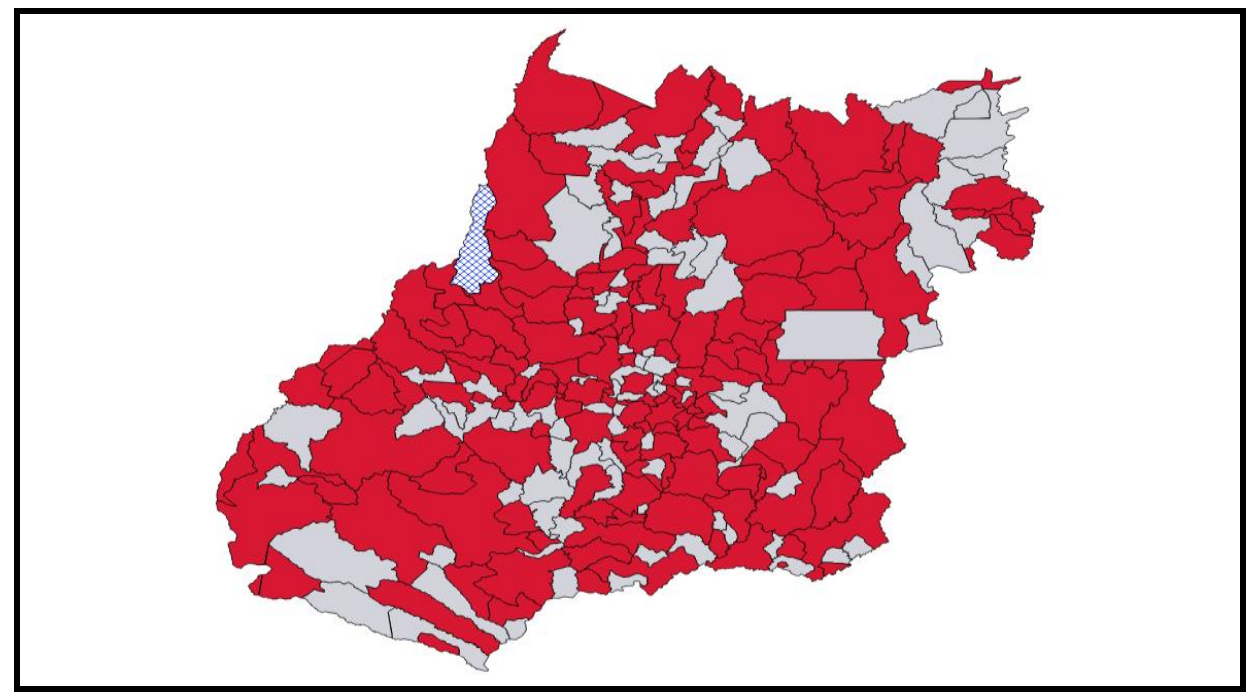

Mapa 2 - Municípios goianos com população indígena residente, 2010. Aruanã em destaque hachurado.

Fonte: arquivo pessoal

Estudos Geográficos, Rio Claro, 17: 106-115, jan./jun. 2019 (ISSN 1678-698X) http://www.periodicos.rc.biblioteca.unesp.br/index.php/estgeo 
Considerando os municípios brasileiros, $52,8 \%$ deles em 2010 possuem população autodeclarada como indígena. Dos 246 municípios goianos, 153 possuem população indígena declarada em 2010, sendo que Aruanã é o segundo no ranking na proporção de população indígena com a proporção de 2,8 indígenas em 2010.

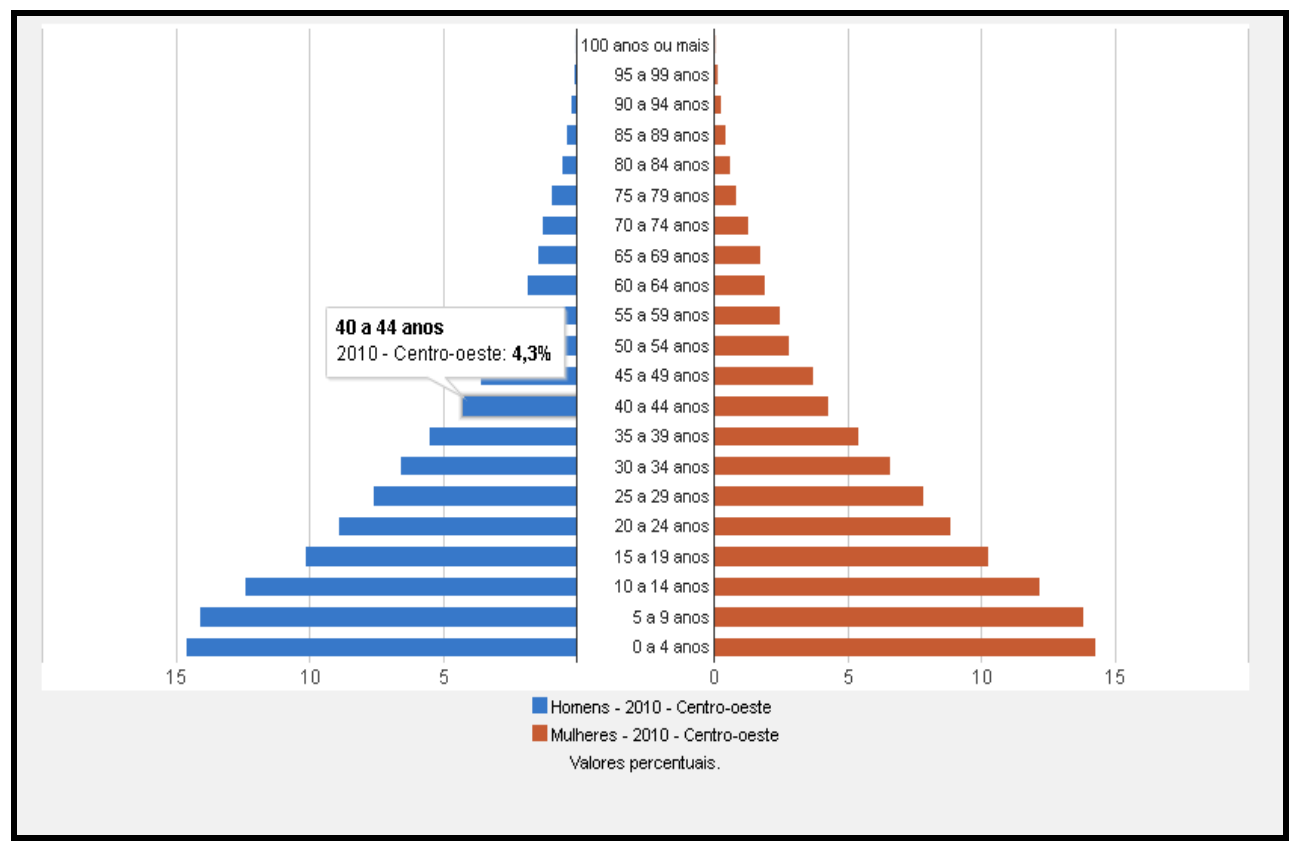

Gráfico 1- pirâmide etária da população indígena declarada na região Centro-Oeste, 2010.

Fonte: https://indigenas.ibge.gov.br/piramide-etaria-2.html

O perfil econômico do município revela o predomínio de comércio conforme a tabela abaixo:

Tabela 3 - Número de empresas por seção do CNAE, no município de Aruanã, 2016.

\begin{tabular}{|l|r|}
\hline 03 Pesca e aquicultura & 1 \\
\hline 08 Extração de minerais não-metálicos & 1 \\
\hline 13 Fabricação de produtos têxteis & 1 \\
\hline 14 Confecção de artigos do vestuário e acessórios & 1 \\
\hline 23 Fabricação de produtos de minerais não-metálicos & 1 \\
\hline 43 Serviços especializados para construção & 1 \\
\hline 68 Atividades imobiliárias & 1 \\
\hline 69 Atividades jurídicas, de contabilidade e de auditoria & 1 \\
\hline 71 Serviços de arquitetura e engenharia; testes e análises técnicas & 1 \\
\hline 77 Aluguéis não-imobiliários e gestão de ativos intangíveis não-financeiros & 1 \\
\hline 86 Atividades de atenção à saúde humana & 1 \\
\hline 10 Fabricação de produtos alimentícios & 2 \\
\hline 25 Fabricação de produtos de metal, exceto máquinas e equipamentos & 2 \\
\hline 49 Transporte terrestre & 2 \\
\hline
\end{tabular}

Estudos Geográficos, Rio Claro, 17: 106-115, jan./jun. 2019 (ISSN 1678-698X) http://www.periodicos.rc.biblioteca.unesp.br/index.php/estgeo 
Análise de situação de saúde do trabalhador...

\begin{tabular}{|l|r|}
\hline 44 Administração pública, defesa e seguridade social & 2 \\
\hline 82 Serviços de escritório, de apoio administrativo e outros serviços prestados às empresas & 3 \\
\hline 45 Comércio e reparação de veículos automotores e motocicletas & 4 \\
\hline 55 Alojamento & 4 \\
\hline 93 Atividades esportivas e de recreação e lazer & 4 \\
\hline 56 Alimentação & 5 \\
\hline 85 Educação & 5 \\
\hline 01 Agricultura, pecuária e serviços relacionados & 6 \\
\hline 81 Serviços para edifícios e atividades paisagísticas & 7 \\
\hline 94 Atividades de organizações associativas & 7 \\
\hline 47 Comércio varejista & 44 \\
\hline Total & 108 \\
\hline
\end{tabular}

Fonte: https://sidra.ibge.gov.br/pesquisa/cempre/quadros/brasil/2016

A distribuição dos trabalhadores nas empresas confirma o comércio varejista e a indústria de transformação como maiores contratantes da região.

Tabela 4 - Proporção de trabalhadores empregados por CNAE

\begin{tabular}{|l|r|}
\hline 47 Comércio varejista & 27,46 \\
\hline C Indústrias de transformação & 4,99 \\
\hline 82 Serviços de escritório, de apoio administrativo e outros serviços prestados às empresas & 4,21 \\
\hline 56 Alimentação & 3,28 \\
\hline 94 Atividades de organizações associativas & 2,18 \\
\hline 45 Comércio e reparação de veículos automotores e motocicletas & 1,25 \\
\hline 55 Alojamento & 1,25 \\
\hline 85 Educação & 0,47 \\
\hline
\end{tabular}

Fonte: https://sidra.ibge.gov.br/pesquisa/cempre/quadros/brasil/2016

Segundo MPT (2019), Aruanã teve 55 notificações de Acidentes de Trabalho o que representa menos de $3 \%$ dos acidentes registrados na região. Segundo estudo recente realizado pelo Centro de Referência em Saúde do Trabalhador (CEREST) do Estado de Goiás com base nos registros no Sistema de Notificação de Agravos (SINAN), a Regional Rio Vermelho teve 319 notificações de acidentes em Saúde do Trabalhador sendo que Aruanã teve um registro de acidente com material biológico e outro acidente grave, o que chama atenção para a subnotificação na rede de atenção saúde. Com base nos dados de trabalhadores celetistas disponíveis no Observatório do Ministério Público do Trabalho - GO nota-se valores diferentes no Agravo Acidente de Trabalho Grave conforme se observa abaixo.

Estudos Geográficos, Rio Claro, 17: 106-115, jan./jun. 2019 (ISSN 1678-698X) http://www.periodicos.rc.biblioteca.unesp.br/index.php/estgeo 
Tabela 5 - Os setores econômicos mais adoecedores de Aruanã 2012-2018

\begin{tabular}{|l|r|l|r|}
\hline Números de afastamentos: & & $\begin{array}{l}\text { Comunicações de acidentes de } \\
\text { trabalho: }\end{array}$ & \\
\hline Criação de bovinos & 3 & Criação de bovinos & 25 \\
\hline $\begin{array}{l}\text { Fabricação de produtos cerâmicos não-refratários } \\
\text { para uso estrutural na construção }\end{array}$ & 3 & Produção de sementes certificadas & 11 \\
\hline Administração pública em geral & 1 & $\begin{array}{l}\text { Atividades de ensino não especificadas } \\
\text { anteriormente }\end{array}$ & 3 \\
\hline $\begin{array}{l}\text { Atividades de ensino não especificadas } \\
\text { anteriormente }\end{array}$ & $\begin{array}{l}\text { Fabricação de produtos cerâmicos não- } \\
\text { refratários para uso estrutural na } \\
\text { construção }\end{array}$ & 3 \\
\hline $\begin{array}{l}\text { Comércio varejista de ferragens, madeira e } \\
\text { materiais de construção }\end{array}$ & & & \\
\hline
\end{tabular}

Fonte: https://observatoriosst.mpt.mp.br/

A rede de atenção em saúde em Aruanã é composta por um hospital, duas unidades de atendimento e uma unidade específica para população indígena. $O$ município não faz parte da rede sentinela para atendimento de acidente grave com material biológico e a população indígena tem direito a um atendimento individualizado.

Tabela 6 - Serviços de Saúde (2009)

\begin{tabular}{|l|r|}
\hline Estabelecimentos de saúde: públicos/SUS & 3 \\
\hline Atendimento de urgência & 1 \\
\hline Unidade com internação & 1 \\
\hline Unidade sem internação & 2 \\
\hline Unidade com atendimento ambulatorial de especialidades & 2 \\
\hline Equipamentos (RX) & 1 \\
\hline Número de leitos para internação & 18 \\
\hline
\end{tabular}

Fonte: https://cidades.ibge.gov.br/brasil/go/aruana/panorama

\section{METODOLOGIAS DE TRABALHO}

Inicialmente, a Regional de Saúde Rio Vermelho que tem o município de Aruanã em sua área de abrangência foi acionada para convocar a rede de atenção municipal e preparar data e local para os encontros. Em seguida, deu-se início a uma recepção comprometida pelos trabalhadores do Sistema Único de Saúde, sendo possível vivenciar a articulação intersetorial com o objetivo maior de conhecer o território da população indígena no âmbito da saúde e da percepção de saúde. Todos os trabalhadores da saúde que participaram não tinham ainda participado de alguma ação de vigilância em saúde nesta perspectiva integrativa e também não iniciaram o processo de planificação da atenção básica proposta pelo Ministério da Saúde.

Foram utilizadas duas estratégias de aproximação: roda de conversa com a rede de atenção local e exposição dialogada com o grupo de pesquisadores do $\mathrm{V}$

Estudos Geográficos, Rio Claro, 17: 106-115, jan./jun. 2019 (ISSN 1678-698X) http://www.periodicos.rc.biblioteca.unesp.br/index.php/estgeo 
Circuito da Sociobiodiversidade. Nestes momentos, participaram Agentes Comunitários de Saúde, Agentes de Endemias, Vigilância sanitária e epidemiológica, fisioterapeuta e fonoaudióloga do Núcleo de Apoio à Saúde da Família (NASF), médico da unidade de saúde da população e da aldeia indígena. O gestor municipal da saúde preparou o auditório da Câmara dos Vereadores como espaço para o evento e acompanhou as discussões.

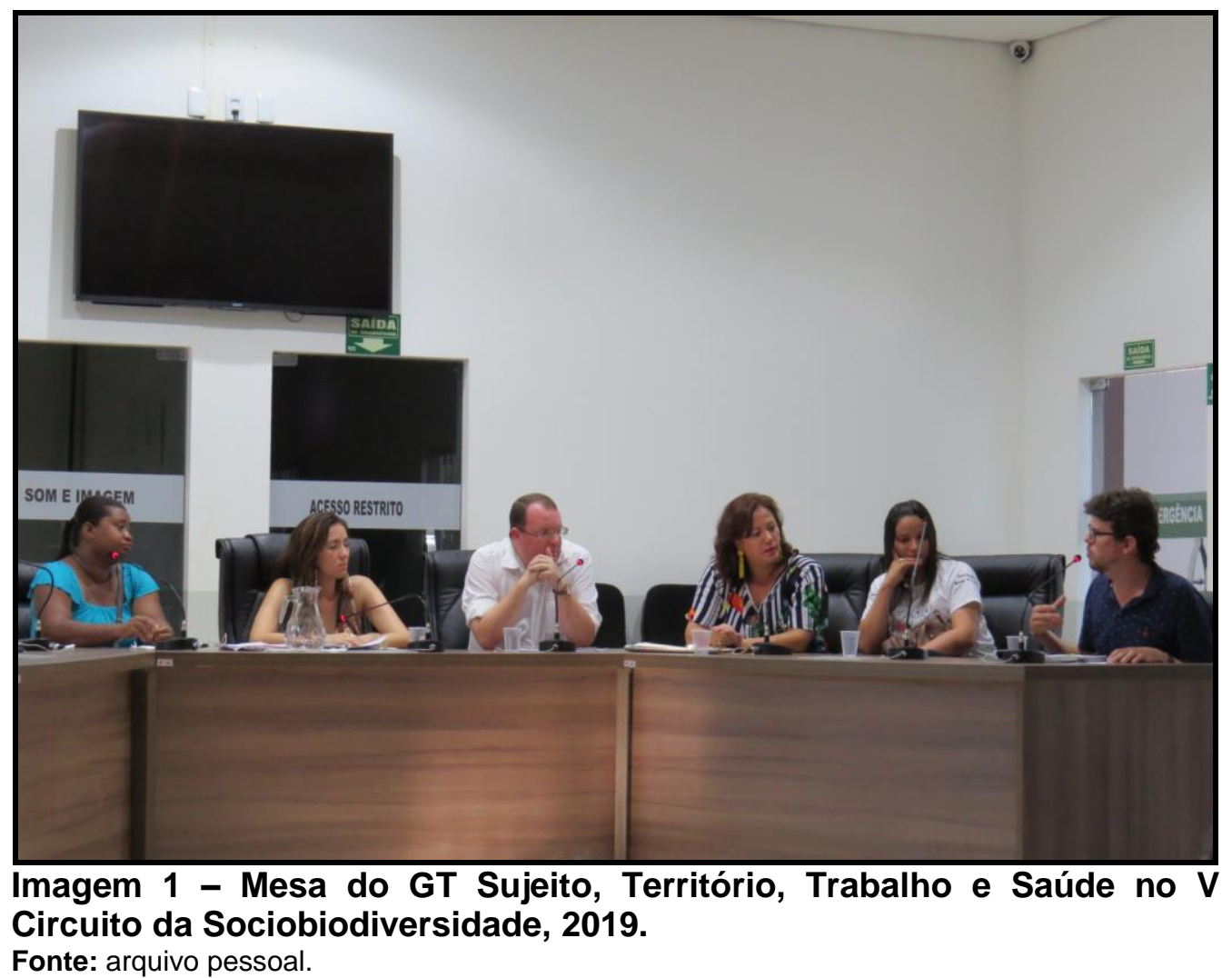

Foi feita também uma visita tímida à Aldeia Buridina e conversa na varanda com o cacique. Optou-se em seguir o grupo de pesquisadores e reprimimos 0 ímpeto de "inspecionar" os riscos e as exposições à saúde dos indígenas na aldeia.

Após as etapas anteriores, segue a análise de saúde relatada e construída a várias falas e a partir de diversos prismas. Caracterizar a população trabalhadora indígena no seu território no jogo de escalas que vai da legislação do SUS, da atenção básica, da aprendizagem vivenciada e da afetividade entre os pares.

O Perfil da população da aldeia segundo relatos é 48 famílias, destas apenas três casais são índios puros, sem nenhuma miscigenação. Na aldeia há em torno de 35 crianças e 300 indígenas ao todo. Consoante relatos dos profissionais de saúde, os índios não se opõem à vacina, nem a fazerem o pré-natal, tampouco ao exame preventivo de câncer de colo de útero, mas tem algumas particularidades: o exame preventivo tem a coleta de material feita na própria aldeia e o exame prénatal é acompanhado presencialmente pelo cacique na aldeia. Participam das palestras de promoção de saúde especificamente dos agentes de endemias. O cacique participa ativamente do Conselho Municipal de Saúde. Segundo relatos, os indígenas executam funções informais de barqueiro, conselheiro de turismo, pesca e aula de artesanato. Há uma tensão no fato de que a gestão financeira dos recursos

Estudos Geográficos, Rio Claro, 17: 106-115, jan./jun. 2019 (ISSN 1678-698X) http://www.periodicos.rc.biblioteca.unesp.br/index.php/estgeo 
para saúde é independente da gestão municipal, porém o repasse tem reduzido gradativamente.

A população indígena se concentra nas 48 casas da aldeia, exceto 03 famílias puras, têm casamentos mistos e os filhos normalmente ficam com a mãe não indígena em casos de separação do casal. Estas crianças têm também livre acesso à rede de atenção à saúde do município e da rede de atenção do indígena. Esta rede específica é composta do Posto de Saúde Indígena Aldeia Buridina, único postinho com dois técnicos de saúde, uma unidade de agentes comunitários enquanto os atendimentos mais complexos acontecem no Hospital Municipal Dr. Claret em Aruanã. Em casos de encaminhamento para os hospitais de alta complexidade, o deslocamento é feito em carro próprio da aldeia ao contrário da população não indígena, que acontece na ambulância do município.

Segundo relato dos trabalhadores da saúde, a prevalência de doenças são as viroses intestinais devido às condições sanitárias na aldeia e a não incorporação da higienização das mãos como hábito. Relatam que nunca tiveram uma formação específica ao atendimento da população indígena e que talvez este "despreparo" seja a causa da discriminação de alguns profissionais para com a população indígena; além do que não há um fluxo de comunicação entre os profissionais que atendem a aldeia e os outros. Assim, apesar da convivência próxima e cotidiana, há disputas entre as populações que ocupam este território por entenderem que a população indígena tem maior acesso ao SUS.

Segundo o profissional médico da rede de atenção do município que também atende a aldeia, já que a unidade de saúde indígena está descoberta há alguns anos, a população indígena precisa de atenção planejada com base no conhecimento da micropopulação e nas especificidades dos seus processos de adoecimento; relata que não se tem pajé na aldeia e que eles preferem alopatia às raízes ou similares; relata uso excessivo de álcool e drogas que resultam em pequenos delitos para manterem o vício; relata perceber uma discriminação maior nos jovens; relata ter conhecido cinco suicídios nos últimos cinco anos incluindo um adolescente indígena. Faz uma discussão ainda sobre a idéia de que os indígenas têm mais facilidades de tratamentos, exames ou medicamentos que a população em geral, pois as políticas de prevenção e promoção da saúde não alcançam os indígenas e que faltam profissionais e medicamentos; neste cenário a população indígena disputa o mesmo fluxo de acesso que o restante dos usuários do SUS. relatadas:

Enfim, seguem trechos de falas que dimensionam algumas condições acima

"Os trabalhadores têm direito no papel enquanto eles (os índios) têm direitos de verdade".

"Não temos assentamentos na região, graças a Deus!".

"Turismo é bom, antes incomodava o som, mas turismo não atrapalha, pelo contrário aumenta venda de artesanatos".

"Face perversa do SUS que não se planejou, não tem objetivos, vive de emendas."

Estudos Geográficos, Rio Claro, 17: 106-115, jan./jun. 2019 (ISSN 1678-698X) 


\section{COMENTÁRIOS}

$\mathrm{Na}$ perspectiva da Vigilância em Saúde do Trabalhador, os encontros realizados durante este evento, as interações entre os diversos profissionais de saúde, a universidade, a assistência e a vigilância e as reflexões construídas coletivamente, dá subsídio para pensarmos que já se inicia uma intervenção política na rede de atenção em saúde local. Fica evidente que numericamente a população indígena do município de Aruanã é relativamente pequena, embora bastante atuante no mercado informal ligado ao turismo local, porém detém uma riqueza natural de terras e águas. Isto os torna mais vulneráveis à exploração do capital, além do fato da aldeia Buridina está em zona urbana, o que os coloca no furacão capital-trabalhosaúde.

Destacamos que há uma disputa de espaço entre a população indígena e não indígena apesar do SUS estar para todos. E a proximidade "geográfica" não garante melhor atuação dos trabalhadores do SUS diante dos conflitos e da problemática identitária da miscigenação entre os povos neste território. Os limites de acesso ao atendimento de saúde não está claro e resulta em um claro mal estar com a população local.

A partir dessa problemática vivenciada e dos diversos pontos de tensão que puderam ser observados e relatados, faz-se urgente que sejam alcançadas outras áreas atuantes na Atenção à Saúde Indígena para conhecer as condições de saúde e ampliar a discussão da população indígena no município de Aruanã. O trabalho da saúde, ainda que permeado pelos conflitos locais, precisa ser melhor discutido e articulado com todas as instâncias, e que outros parceiros possam ser solidários, para que a população possa ser melhor assistida.

\section{REFERÊNCIAS}

ANTUNES, Ricardo. O Privilégio da Servidão: o novo proletariado de serviços na era digital. 1 Ed. São Paulo - Boitempo, 2018.

MARX, Karl. O Capital. Vol. 2. 3ª edição, São Paulo, Nova Cultural, 1988.

TEIXEIRA, CF., PAIM, JS., e VILASBÔAS, AL. SUS, Modelos assistenciais e Vigilância da Saúde. In: ROZENFELD, S., org. Fundamentos da Vigilância Sanitária [online]. Rio de Janeiro: Editora FIOCRUZ, 2000.

Estudos Geográficos, Rio Claro, 17: 106-115, jan./jun. 2019 (ISSN 1678-698X) 